International Journal of

Environmental Research and

Public Health

ISSN 1660-4601

www.mdpi.com/journal/ijerph

Article

\title{
Association between Hypertension and Chronic Arsenic Exposure in Drinking Water: A Cross-Sectional Study in Bangladesh
}

Mohammad Rafiqul Islam ${ }^{1}$, Ismail Khan ${ }^{2}$, John Attia ${ }^{1}$, Sheikh Mohammad Nazmul Hassan ${ }^{3}$, Mark McEvoy ${ }^{1}$, Catherine D'Este ${ }^{1}$, Syed Azim ${ }^{4}$, Ayesha Akhter ${ }^{5}$, Shahnaz Akter ${ }^{6}$, Sheikh Mohammad Shahidullah ${ }^{7}$ and Abul Hasnat Milton ${ }^{1, *}$

1 Centre for Clinical Epidemiology \& Biostatistics (CCEB), The University of Newcastle, Lot 1 Kookaburra Circuit, New Lambton Heights, NSW 2305, Australia;

E-Mails: mdrafiqul.islam@newcastle.edu.au (M.R.I.); John.Attia@newcastle.edu.au (J.A.); Mark.McEvoy@newcastle.edu.au (M.M.); Catherine.dEste@newcastle.edu.au (C.D.)

2 Department of Pharmacology, Dhaka Medical College, Dhaka 1000, Bangladesh; E-Mail: ismailbangladesh@yahoo.com

3 Department of Public Health, Atish Dipankar University of Science \& Technology, Dhaka 1205, Bangladesh; E-Mail: nazmulhena@yahoo.com

4 School of Public Health and Community Medicine, University of New South Wales, Sydney, NSW 2052, Australia; E-Mail: s.azim@unsw.edu.au

5 Department of Obstetrics and Gynaecology, Tairunnessa Memorial Medical College, Targas, Kunia, Gazipur, Dhaka, Gazipur 1701, Bangladesh; E-Mail: akhterayesha@yahoo.com.au

6 Department of Paediatrics, Institute of Child and Mother Health (ICMH), Matuail, Demra, Dhaka 1362, Bangladesh; E-Mail: nupur.dmc56@gmail.com

7 NGO Forum for Drinking Water, Lalmatia, Dhaka 1207, Bangladesh;

E-Mail: smshahidullah@gmail.com

* Author to whom correspondence should be addressed; E-Mail: milton.hasnat@newcastle.edu.au; Tel.: +61-2-4042-0525; Fax: +61-2-4042-0041.

Received: 12 October 2012; in revised form: 27 November 2012 / Accepted: 29 November 2012 / Published: 7 December 2012

Abstract: Chronic arsenic exposure and its association with hypertension in adults are inconclusive and this cross-sectional study investigated the association. The study was conducted between January and July 2009 among 1,004 participants from 1,682 eligible women and men aged $\geq 30$ years living in rural Bangladesh who had continuously 
consumed arsenic-contaminated drinking water for at least 6 months. Hypertension was defined as systolic blood pressure $\geq 140 \mathrm{mmHg}$ (systolic hypertension) and diastolic blood pressure $\geq 90 \mathrm{mmHg}$ (diastolic hypertension). Pulse pressure was calculated by deducting diastolic from systolic pressure and considered to be increased when the difference was $\geq 55 \mathrm{mmHg}$. The prevalence of hypertension was $6.6 \%$ (95\% CI: $5.1-8.3 \%$ ). After adjustment for other factors, no excess risk of hypertension was observed for arsenic exposure $>50 \mu \mathrm{g} / \mathrm{L}$ or to that of arsenic exposure as quartiles or as duration. Arsenic concentration as quartiles and $>50 \mu \mathrm{g} / \mathrm{L}$ did show a strong relationship with increased pulse pressure (adjusted OR: 3.54, 95\% CI: 1.46-8.57), as did arsenic exposure for $\geq 10$ years (adjusted OR: 5.25, 95\% CI: 1.41-19.51). Arsenic as quartiles showed a dose response relationship with increased pulse pressure. Our study suggests an association between higher drinking water arsenic or duration and pulse pressure, but not hypertension.

Keywords: arsenic; drinking-water; hypertension; pulse-pressure; Bangladesh

\section{Introduction}

Arsenic is a toxic metalloid that is found in various compounds in the soil and extensively distributed in the Earth's crust [1,2]. Exposure to inorganic arsenic via drinking water, occupation, medication, and other sources has wide ranging effects on health conditions, based on data from many parts of the World [1,3-5]. These health effects range from skin lesions, stillbirth, spontaneous abortion, poor nutritional status during pregnancy, cardiovascular diseases, diabetes to cancers of many types [6-13]. On the other hand, cessation of arsenic contaminated artesian well water consumption in Taiwan decreased the mortality from peripheral vascular disease and ischemic heart disease $[14,15]$ and arsenic exposure is likely to be causal of ischemic heart disease related mortality [15]. Ingested inorganic arsenic may directly affect the atherogenic process involving vascular endothelium, smooth muscle cells, platelets and macrophages and can cause black foot disease and ischemic heart disease; arsenic may also indirectly affect many risk factors for cardiovascular diseases [1].

Among the cardiovascular risk factors, hypertension is a well-known and widespread. Hypertension is generally defined as abnormally high arterial blood pressure indicated by an adult systolic blood pressure of $140 \mathrm{mmHg}$ or greater or a diastolic blood pressure of $90 \mathrm{~mm} \mathrm{Hg}$ or greater [16]. In addition to general hypertension, an increased risk of vascular disease is associated with many other blood pressure dimensions such as systolic (SBP), diastolic (DBP), mean arterial (defined as $1 / 3 \times(\mathrm{SBP}+2 \times \mathrm{DBP})$ ) and pulse pressure (the difference between SBP and DBP) [17]. Globally, approximately one billion adult people are suffering from hypertension, of which $66 \%$ are from developing countries [18]. In the industrialized countries, it is one of the most important risk factors for death [19]. About 90-95\% of hypertensive cases are suffering from primary or essential hypertension while the rest are from secondary causes such as reno-vascular and endocrine disorders [20-22]. Important known associated risk factors for primary hypertension are sedentary lifestyles, hypokalaemia, obesity, higher body mass 
index (BMI), sensitivity to table salt, high alcohol consumption, ageing, having a positive family history, low birth weight, insulin resistance and metabolic syndrome [23-32].

Chronic arsenic toxicity via drinking water consumption has been significantly associated with hypertension in many ecological studies. Chronic arsenic exposure was associated with increased systolic and diastolic blood pressure in a village population in Iran [33]. One Indian study showed higher liver arsenic concentrations among those who drank arsenic contaminated water and reported a possible association with idiopathic portal hypertension [34]. A few studies conducted in Taiwan reported dose response relationships of chronic arsenic exposure with hypertension and cerebrovascular diseases [1,35]. A Bangladeshi study estimated a doubling in the risk of being hypertensive in people exposed to one milligram of arsenic in each litre, compared to less than 0.5 milligram per litre of drinking water [36]. Another Bangladeshi study reported no association of arsenic to overall and diastolic hypertension but observed an association with increased pulse pressure and systolic hypertension and recommended further studies to investigate the relationship of low-levels of drinking water arsenic exposure with atherosclerosis and cardiovascular diseases [17]. However, the dose response relationship and toxicological mechanism of arsenic on hypertension are still unclear [37]. Therefore, we aimed to evaluate hypertension in rural Bangladeshi adults on or over 30 years of age exposed to various levels of drinking water arsenic at least for a period of six months.

\section{Methods}

\subsection{Overview}

Bangladesh is divided into 64 districts, with each district divided into sub-districts named upazilas, and each upazila further divided into a number of unions. Each union consists of a number of villages, each with a number of tube wells from which the inhabitants draw their water for daily usage including drinking and cooking. Ethics approval was obtained from the Bangladesh Medical Research Council (BMRC) and the Human Research Ethics Committee (HREC), The University of Newcastle, Australia.

\subsection{Design, Study Area and Population}

This cross sectional study was conducted between January and July 2009 in Bangladesh. We reviewed the Bangladesh Arsenic Mitigation Water Supply Project's (BAMWSP) national survey report and arsenic contaminated areas were selected. Four unions of Laksam upazila and one union of Monohargonj upazila of Comilla district were chosen as high; two unions of Kaliganj upazila of Jhenidah district were chosen as low arsenic contaminated areas. A union having $\geq 40 \%$ of the tube wells contaminated with arsenic $>50 \mu \mathrm{g} / \mathrm{L}$, of which $25 \%$ had arsenic more than $250 \mu \mathrm{g} / \mathrm{L}$ were considered as a high arsenic contaminated area. A union with no tube well containing arsenic at or more than $50 \mu \mathrm{g} / \mathrm{L}$ was considered as a low arsenic contaminated area. These areas were chosen purposively to ensure the study population's exposure to a wide range of arsenic that enabled us to study the effect of various levels of arsenic on hypertension. Comilla and Jhenidah districts are $100 \mathrm{~km}$ south-east and $180 \mathrm{~km}$ south-west from Dhaka city, the capital of Bangladesh, respectively. One hundred households were randomly selected from each of the seven unions. All individuals present during the household visit who fulfilled eligibility criteria were recruited in the study after 
obtaining their informed verbal consent. Eligibility criteria were: aged $\geq 30$ years, history of drinking water from any tube well for at least 6 months continuously, and resident in the study area for at least the preceding 6 months.

\subsection{Data Collection Procedure}

Trained field workers conducted a door to door survey to identify potential participants from the randomly selected households. Since the literacy rate was low, the study information sheet was read directly to the potential participants, and the objectives and expectations of the study were comprehensively explained. Field workers then obtained informed verbal consent.

Interviewers collected information on socio-demographics, and drinking water use history using a structured questionnaire. The questionnaire was developed by the researchers and pretested in a neighbouring village similar to the study area. All participants underwent a full body examination by a physician under sunlight to investigate the presence of arsenical skin lesions, i.e., melanosis, leucomelanosis and keratosis. Standing height and weight of each participant were measured with the subjects wearing light clothes and no shoes. Weight was measured in kilograms using bathroom scales (Precision $500 \mathrm{gm}$ ) that were calibrated daily and zeroed before each measurement. Height was measured in centimetres using a locally made wooden height board with a metal measurement tape attached.

\subsection{Exposure Measurement}

A single well water measurement was used to characterize chronic arsenic exposure for each participant. In the case of participants who changed their drinking source following BAMWSP survey, we collected water samples from the previous tubewell and duration of use. Cumulative arsenic exposure was calculated by multiplying the arsenic content of the tube well with duration of use. Drinking water samples were transferred and analysed following standard procedure [38]. Water arsenic analyses were performed at a Water Quality Testing Laboratory in Dhaka using flow injection-hydride generation atomic absorption spectrometry (FIHG-AAS) [38]. Minimum detection level of arsenic by this method is $3 \mu \mathrm{g} / \mathrm{L}$.

\subsection{Outcome Definition and Measurement}

In this study we defined overall hypertension as a systolic blood pressure $\geq 140 \mathrm{mmHg}$ (or systolic hypertension) combined with a diastolic blood pressure $\geq 90 \mathrm{mmHg}$ (or diastolic hypertension), as used previously in other studies [36,39]. We measured blood pressure from a participant in sitting position and in a calm and quiet environment after $15 \mathrm{~min}$. This procedure followed according to the recommendation by the World Health Organization [40]. Each participant's blood pressure was measured for 3 times on the day of visit, and for this study we considered the lowest measured value. For those with known hypertension and on antihypertensive medication $(\mathrm{n}=12)$, we used the median pressure of the newly diagnosed hypertensive cases in this study. We also calculated pulse pressure by deducting diastolic from systolic pressure and defined increased pulse pressure if the difference was $\geq 55 \mathrm{mmHg}$ [17]. 


\subsection{Other Variables}

Information on socio-demographic characteristics such as age, sex, income, education and occupation, marital status, drinking water history, smoking history, height, weight, arsenical skin lesions, family history of hypertension and diabetes were collected. Body Mass Index (BMI) was also calculated using the standard method (weight in $\mathrm{kg} /\left(\right.$ height in meter) ${ }^{2}$ ) [41].

\subsection{Statistical Analysis}

Data were analysed using STATA version 10 supplied by STATA Corporation, TX, USA. Frequency tables and summary statistics were obtained to check missing data, out of range values and to assess distributions of continuous variables; logic checks were also undertaken. Water arsenic level was used to characterise chronic arsenic exposure. Arsenic concentration was categorised by the maximum acceptable limit in drinking water in Bangladesh, i.e., $\leq 50 \mu \mathrm{g} / \mathrm{L}$ and $>50 \mu \mathrm{g} / \mathrm{L}$ and also as quartiles; for each arsenic exposure categories, duration of exposure was categorised as $\leq 10$ years and $>10$ years.

Multiple logistic regressions were done to determine the association between chronic arsenic exposure and hypertension, adjusting for potential confounders. Potential confounders such as participant's age, sex, education, occupation, marital status, religion, total number of household members, income, smoking history, self-reported diabetes and body mass index $(<18.2$ as malnourished and $\geq 18.2$ as normal) were included in the initial model. Only those variables found to be significant at $P<0.25$ level of significance in the initial model were included in the final multiple regression model. We also used arsenic quartiles and modeled multiple logistic regressions to determine the association of higher levels of arsenic to that of hypertension. Cuzick's nonparametric test for trend was used to test the trend across ordered groups.

\section{Results}

This study was conducted in 1,004 consenting women and men from 1,682 eligible participants yielding a participation rate of $60 \%$. Approximately two third of the participants were female housewives and about $69 \%$ of the participants did not have any formal education. The participants' mean age and BMI were 44.9 years $( \pm 13.2)$ and $20.3( \pm 4.5)$, respectively and nearly $99 \%$ of them were ever married. About $33 \%$ of the participants had a lean BMI $(<18.22)$ and a similar proportion were employed. Average monthly household income was 59 US\$ $( \pm 56,1$ US\$ $=80$ Taka in Bangladesh currency). Of the participants, $14.2 \%$ were current smoker with a mean duration of smoking of 22.6 years $( \pm 12.9)$. Participants were mostly Muslim $(77 \%)$ and 39\% of the participants had different forms of arsenical skin lesions. Age and sex distributions of participants across the study areas were similar, although other socio-demographic characteristics such as education, monthly household income, BMI, arsenic concentration in drinking water, duration of arsenic exposure and history of hypertension differed substantially. About $50 \%$ of the Hindu participants and $29.5 \%$ of the Muslims were obese $(\mathrm{BMI}>21)$. Arsenic concentration in the drinking water ranged from 10 to $1,401 \mu \mathrm{g} / \mathrm{L}$ and $46.4 \%$ of the survey household's drinking water contained arsenic $>50 \mathrm{ug} / \mathrm{L}$. 
Table 1. Mean values of systolic blood pressure, diastolic blood pressure and pulse pressure.

\begin{tabular}{|c|c|c|c|c|c|c|c|c|c|}
\hline & \multicolumn{3}{|c|}{ Overall $(n=1004)$} & \multicolumn{2}{|c|}{ SBP * } & \multicolumn{2}{|r|}{ DBP * } & \multicolumn{2}{|c|}{ Pulse blood pressure * } \\
\hline & No & $\%$ & $\begin{array}{c}\text { Mean As Conc* } \\
(\mu g / \text { liter, SD) }\end{array}$ & $\begin{array}{c}\text { Mean } \\
(\mathrm{mmHg}, \mathrm{SD})\end{array}$ & $\begin{array}{c}\text { Systolic } \\
\text { hypertension (SBP, } \\
\geq 140 \mathrm{mmHg}), \%\end{array}$ & $\begin{array}{c}\text { Mean } \\
(\mathrm{mmHg}, \\
\text { SD) }\end{array}$ & $\begin{array}{c}\text { Diastolic } \\
\text { hypertension (DBP, } \\
\geq 90 \mathrm{mmHg}) \%\end{array}$ & $\begin{array}{c}\text { Mean } \\
(\mathrm{mmHg}, \\
\text { SD) }\end{array}$ & $\begin{array}{l}\text { High pulse pressure } \\
\text { ( } \geq 55 \mathrm{mmHg}), \%\end{array}$ \\
\hline \multicolumn{10}{|l|}{ Gender } \\
\hline Female & 687 & 68.4 & $143.3, \pm 185.3$ & $110.3, \pm 15.9$ & 9.8 & $73.1, \pm 10.5$ & 10.9 & $37.1, \pm 8.8$ & 3.3 \\
\hline Male & 317 & 31.6 & $192.2, \pm 220.8$ & $114.0, \pm 16.4$ & 6.7 & $75.3, \pm 11.3$ & 12.3 & $38.7, \pm 9.1$ & 5.7 \\
\hline \multicolumn{10}{|l|}{ Age (years) } \\
\hline $30-39$ & 405 & 40.3 & $157.5, \pm 187.2$ & $109.2, \pm 13.0$ & 2.5 & $72.9, \pm 8.6$ & 5.4 & $36.4, \pm 7.0$ & 1.0 \\
\hline $40-49$ & 263 & 26.2 & $159.5, \pm 202.4$ & $109.2, \pm 15.7$ & 5.3 & $72.4, \pm 10.8$ & 9.5 & $36.8, \pm 8.7$ & 3.0 \\
\hline $50-59$ & 156 & 15.6 & $146.5, \pm 194.9$ & $113.1, \pm 16.5$ & 10.3 & $74.6, \pm 11.8$ & 15.4 & $38.5, \pm 9.0$ & 5.1 \\
\hline$\geq 60$ & 180 & 17.9 & $171.1, \pm 220.2$ & $118.3, \pm 21.5$ & 20.6 & $77.3, \pm 13.3$ & 23.9 & $41.0, \pm 11.9$ & 11.7 \\
\hline \multicolumn{10}{|l|}{ BMI *(tertiles) } \\
\hline$<18.22$ & 328 & 33.0 & $202.2, \pm 224.7$ & $106.8, \pm 17.2$ & 7.0 & $70.6, \pm 11.2$ & 7.6 & $36.1, \pm 9.7$ & 3.7 \\
\hline $18.22-21.33$ & 333 & 33.0 & $158.5, \pm 195.8$ & $111.4, \pm 14.8$ & 5.4 & $74.0, \pm 10.1$ & 10.2 & $37.5, \pm 8.6$ & 4.2 \\
\hline$>21.33$ & 343 & 34.0 & $117.4, \pm 162.7$ & $116.0, \pm 15.0$ & 10.5 & $76.7, \pm 10.2$ & 16.0 & $39.3, \pm 8.3$ & 4.4 \\
\hline \multicolumn{10}{|l|}{ Education } \\
\hline No education & 694 & 69.1 & $155.4, \pm 199.4$ & $111.6, \pm 17.0$ & 9.2 & $73.9, \pm 11.3$ & 12.5 & $37.8, \pm 9.4$ & 4.9 \\
\hline Primary & 186 & 18.5 & $150.5, \pm 179.7$ & $111.0, \pm 14.6$ & 5.4 & $72.9, \pm 10.2$ & 10.2 & $38.0, \pm 8.4$ & 2.7 \\
\hline Secondary & 124 & 12.4 & $190.0, \pm 218.0$ & $111.2, \pm 12.8$ & 2.4 & $74.9, \pm 8.2$ & 6.4 & $36.3, \pm 6.8$ & 1.6 \\
\hline \multicolumn{10}{|l|}{ Religion } \\
\hline Muslim & 766 & 76.3 & $196.3, \pm 207.7$ & $110.1, \pm 15.9$ & 6.1 & $73.0, \pm 10.5$ & 9.9 & $37.2, \pm 9.3$ & 3.9 \\
\hline Hindu & 238 & 23.7 & $37.8, \pm 90.2$ & $115.7, \pm 16.3$ & 12.6 & $76.6, \pm 11.2$ & 16.0 & $39.2, \pm 7.4$ & 4.6 \\
\hline \multicolumn{10}{|l|}{ Marital status } \\
\hline Currently married & 862 & 85.9 & $160.7, \pm 201.7$ & $111.3, \pm 15.6$ & 7.0 & $73.8, \pm 10.5$ & 10.9 & $37.6, \pm 8.7$ & 3.7 \\
\hline Widowed/divorced & 131 & 13.0 & $141.5, \pm 178.4$ & $112.5, \pm 19.1$ & 12.2 & $74.2, \pm 12.4$ & 14.5 & $38.3, \pm 10.8$ & 6.9 \\
\hline Never married & 11 & 1.1 & $210.4, \pm 167.4$ & $110.0, \pm 17.6$ & 9.1 & $72.5, \pm 12.4$ & 9.1 & $36.5, \pm 7.6$ & 0.0 \\
\hline \multicolumn{10}{|l|}{ Monthly income } \\
\hline$\leq 50 \$(1 \$=80 \mathrm{tk})$ & 537 & 53.5 & $151.0, \pm 196.0$ & $112.2, \pm 17.3$ & 10.2 & $74.0, \pm 11.3$ & 12.6 & $38.1, \pm 9.5$ & 4.7 \\
\hline$>50 \$$ & 467 & 46.5 & $167.7, \pm 201.1$ & $110.6, \pm 14.6$ & 4.7 & $73.6, \pm 10.2$ & 10.1 & $37.1, \pm 8.3$ & 3.4 \\
\hline
\end{tabular}


Table 1. Cont.

\begin{tabular}{|c|c|c|c|c|c|c|c|c|c|}
\hline & \multicolumn{3}{|c|}{ Overall $(n=1004)$} & \multicolumn{2}{|c|}{ SBP * } & \multicolumn{2}{|r|}{ DBP * } & \multicolumn{2}{|c|}{ Pulse blood pressure * } \\
\hline & No & $\%$ & $\begin{array}{c}\text { Mean As Conc * } \\
(\mu \mathrm{g} / \mathrm{liter}, \mathrm{SD})\end{array}$ & $\begin{array}{c}\text { Mean } \\
(\mathrm{mmHg}, \mathrm{SD})\end{array}$ & $\begin{array}{c}\text { Systolic } \\
\text { hypertension (SBP, } \\
\geq 140 \mathrm{mmHg}), \%\end{array}$ & $\begin{array}{c}\text { Mean } \\
(\mathrm{mmHg}, \\
\text { SD) }\end{array}$ & $\begin{array}{c}\text { Diastolic } \\
\text { hypertension (DBP, } \\
\geq 90 \mathrm{mmHg}) \%\end{array}$ & $\begin{array}{c}\text { Mean } \\
(\mathrm{mmHg}, \\
\text { SD) }\end{array}$ & $\begin{array}{c}\text { High pulse pressure } \\
\text { ( } \geq 55 \mathrm{mmHg}), \%\end{array}$ \\
\hline \multicolumn{10}{|l|}{ Arsenical skin lesions } \\
\hline No lesions & 614 & 61.2 & $102.5, \pm 154.7$ & $113.0, \pm 15.7$ & 9.0 & $74.9, \pm 10.8$ & 13.4 & $72.0, \pm 10.8$ & 3.4 \\
\hline Melanosis & 83 & 8.2 & $177.3, \pm 196.4$ & $108.1, \pm 15.2$ & 4.8 & $72.5, \pm 9.5$ & 7.2 & $35.5, \pm 8.1$ & 2.4 \\
\hline Keratosis & 34 & 3.4 & $250.7, \pm 270.0$ & $104.1, \pm 14.4$ & 2.9 & $71.2, \pm 10.7$ & 2.9 & $32.9, \pm 8.3$ & 0.0 \\
\hline Leucomelanosis & 273 & 27.2 & $268.1, \pm 224.8$ & $109.9, \pm 17.0$ & 6.2 & $72.0, \pm 10.8$ & 9.2 & $38.0, \pm 11.3$ & 6.6 \\
\hline \multicolumn{10}{|l|}{$\begin{array}{l}\text { * As exp. by quartile } \\
(\mu \mathrm{g} / \mathrm{L})\end{array}$} \\
\hline 1st quartile (10-22) & 296 & 29.5 & $16.5, \pm 4.7$ & $112.2, \pm 15.0$ & 7.8 & $74.9, \pm 10.9$ & 10.8 & $37.2, \pm 7.4$ & 1.7 \\
\hline 2nd quartile (23-32) & 209 & 20.8 & $28.5, \pm 3.5$ & $112.1, \pm 17.4$ & 10.5 & $74.1, \pm 10.6$ & 13.9 & $38.0, \pm 9.6$ & 4.8 \\
\hline 3rd quartile (33-261) & 253 & 25.2 & $141, \pm 67.7$ & $110.4, \pm 16.5$ & 5.9 & $73.4, \pm 10.9$ & 11.1 & $37.0, \pm 8.8$ & 4.0 \\
\hline 4th quartile $(\geq 262)$ & 246 & 24.5 & $458.5, \pm 164.6$ & $111.1, \pm 16.0$ & 6.9 & $72.7, \pm 10.6$ & 10.2 & $38.5, \pm 10.2$ & 6.5 \\
\hline
\end{tabular}

* SBP: Systolic blood pressure, ${ }^{*}$ DBP: Diastolic blood pressure; * Mean As Conc.: Mean arsenic concentration in drinking water; 团: Prevalence of systolic, diastolic and pulse pressure; *As: Arsenic.

Table 2. Association of arsenic concentration with overall Hypertension, Systolic Hypertension, Diastolic Hypertension and Pulse pressure $(\mathrm{n}=994)$.

\begin{tabular}{|c|c|c|c|c|c|c|c|c|c|c|c|c|}
\hline \multirow{2}{*}{$\begin{array}{l}\text { Arsenic } \\
\text { Concentration *, (N) }\end{array}$} & \multicolumn{3}{|c|}{ Overall hypertension } & \multicolumn{3}{|c|}{ Systolic hypertension $\$$} & \multicolumn{3}{|c|}{ Diastolic hypertension ${ }^{\psi}$} & \multicolumn{3}{|c|}{ Increased pulse pressure $^{\varphi}$} \\
\hline & $\begin{array}{l}\text { No. of } \\
\text { cases }\end{array}$ & $\begin{array}{l}\text { Adjusted } \\
\text { OR }\end{array}$ & $95 \% \mathrm{CI}$ & $\begin{array}{c}\text { No. of } \\
\text { cases }\end{array}$ & $\begin{array}{l}\text { Adjusted } \\
\text { OR }\end{array}$ & $95 \% \mathrm{CI}$ & $\begin{array}{l}\text { No. of } \\
\text { cases }\end{array}$ & $\begin{array}{l}\text { Adjusted } \\
\text { OR } \\
\end{array}$ & $95 \% \mathrm{CI}$ & $\begin{array}{l}\text { No. of } \\
\text { cases }\end{array}$ & $\begin{array}{c}\text { Adjusted } \\
\text { OR } \\
\end{array}$ & $95 \% \mathrm{CI}$ \\
\hline$<50(532) \dagger$ & 43 & - & - & 47 & - & - & 64 & - & - & 15 & - & - \\
\hline$>50(462)$ & 23 & 0.93 & $0.49-1.78$ & 30 & 1.11 & $0.61-2.02$ & 50 & 1.24 & $0.76-2.01$ & 26 & 3.54 & $1.46-8.57$ \\
\hline
\end{tabular}

* Arsenic Concentration.: Drinking water arsenic concentration in microgram/liter; ${ }^{\circledR}$ Systolic hypertension: Systolic blood pressure $\geq 140 \mathrm{mmHg} ;{ }^{*}$ Diastolic hypertension: Diastolic blood pressure $\geq 90 \mathrm{mmHg},{ }^{\varphi}$ Pulse pressure: categorized as $<55 \mathrm{mmHg}$ and $\geq 55 \mathrm{mmHg} ; 95 \%$ CI: $95 \%$ Confidence interval. ${ }^{\dagger}$ Reference category. Adjusted for age, sex, education, marital status, religion, monthly income and BMI. ** Crude Odds Ratios: For overall hypertension 0.60 (CI: $0.35-1.01$ ), systolic hypertension 0.72 (CI: 0.45-1.15), diastolic hypertension 0.89 (CI: 0.60-1.31) and for increased pulse pressure 2.06 (CI: 1.07-3.93). 
Overall prevalence of hypertension among the study participants was $6.6 \%$ (male $8.2 \%$ and female $5.8 \%$ ) while $12.3 \%$ of the participants reported a family history of hypertension. Systolic hypertension was identified in 7.7\% (male 9.8\%, female 6.7\%) and diastolic hypertension in $11.3 \%$ (male $12.3 \%$, female $10.9 \%$ ) of the participants, although only $4.1 \%$ (male $5.7 \%$ and female $3.3 \%$ ) had an increased pulse pressure ( $\geq 55 \mathrm{mmHg}$ ). Means of arsenic concentration, systolic blood pressure, diastolic blood pressure and pulse pressure by participant's characteristics were presented in Table 1.

In simple regression, Hindu participants were more likely to have hypertension compared to Muslims (OR 2.5, CI: 1.5-4.2). Participants with primary or high school education were 44\% less likely to have hypertension than those having no formal education. There was a $5 \%$ increase in risk of having hypertension with each year increase of age and each unit increase of BMI. Table 2 shows the results of multiple regression analysis with overall hypertension by exposure to arsenic categories $\leq 50 \mu \mathrm{g} / \mathrm{L}$ and $>50 \mu \mathrm{g} / \mathrm{L}$, adjusted for sex, age, education, marital status, religion, monthly income, and BMI. The results shows no excess risk of overall, systolic, or diastolic hypertension for arsenic concentration $>50 \mu \mathrm{g} / \mathrm{L}$. Another similar adjusted multiple regression analysis by gender were performed (analysis not shown) and did not find any difference in overall and systolic hypertension but did show an association in males for diastolic hypertension (adj. OR $=3.83,95 \% \mathrm{CI}$ : 1.16-12.68) and in females for increased pulse pressure (adj. OR $=5.10,95 \% \mathrm{CI}$ : $1.59-16.38$ ) when exposed to arsenic concentration $>50 \mu \mathrm{g} / \mathrm{L}$. In secondary analyses using continuous blood pressure and arsenic as continuous exposure values, results were similarly non-significant for diastolic pressure but there was a borderline positive association with arsenic and systolic pressure (coefficient 0.005 , CI: -0.0 to 0.01 , $P=0.05)$. However, arsenic exposure $>50 \mu \mathrm{g} / \mathrm{L}$ was found to be strongly associated with increased pulse pressure when adjusted for other factors (OR $=3.54,95 \% \mathrm{CI}: 1.46-8.57)$.

We further categorized arsenic concentrations according to quartiles and a multiple logistic regression adjusted for age, sex, education, marital status, religion, monthly income, and BMI found no effect on overall, systolic or diastolic hypertension, but did find a strong increased effect on pulse pressure (Table 3). There was an increasing trend in association with the increase of arsenic exposure levels in drinking water $(P$ for trend $<0.01)$.

Table 3. Association of overall hypertension and increased pulse pressure to that of arsenic concentration by quartiles $(\mathrm{n}=994)$.

\begin{tabular}{cccccccc}
\hline $\begin{array}{c}\text { As_Conc. } \\
\text { quartile } \\
(\boldsymbol{\mu g} / \mathbf{L})\end{array}$ & $\mathbf{N}$ & & \multicolumn{3}{c}{ Overall Hypertension } & \multicolumn{3}{c}{ Pulse Pressure } \\
\cline { 3 - 8 } & & No. of cases & Adj. OR & $\mathbf{9 5 \%}$ CI & No of cases & Adj. OR & 95\% CI \\
\hline $10-22 *$ & 291 & 22 & - & - & 5 & - & - \\
$23-32$ & 208 & 19 & 1.33 & $0.67-2.62$ & 10 & 3.87 & $1.22-12.20$ \\
$33-261$ & 252 & 13 & 1.10 & $0.49-2.44$ & 10 & 4.32 & $1.23-15.11$ \\
$\geq 262$ & 243 & 12 & 0.96 & $0.42-2.23$ & 16 & 7.32 & $2.18-24.60$ \\
\hline
\end{tabular}

$P$ for trend $<0.01$ : Cuzick's non parametric test for trend across quartiles of exposure groups; all four groups were assessed in the trend test; * Reference category. Adjusted for age, sex, education, marital status, religion, monthly income and BMI; ${ }^{0}$ Pulse pressure were categorized $<55$ and $\geq 55 \mathrm{mmHg}$; ** Crude Odds Ratios: For overall hypertension, 2nd quartile 1.24 (CI: 0.65-2.36), 3rd quartile 0.67 (0.33-1.36), 4th quartile 0.64 (0.31-1.31); For increased pulse pressure, 2nd quartile 2.92 (CI: 0.98-8.68), 3rd quartile 2.39 (0.81-7.10), 4 th quartile 4.04 (1.46-11.21). 
Again, we categorized exposure to arsenic contaminated drinking water by $\leq 50 \mu \mathrm{g} / \mathrm{L}$ and $>50 \mu \mathrm{g} / \mathrm{L}$ concentration and also by duration, i.e., $<10$ and $\geq 10$ years and performed the analysis together using all four exposure categories $(\leq 50 \mu \mathrm{g} / \mathrm{L}$ and $<10$ years, $>50 \mu \mathrm{g} / \mathrm{L}$ and $<10$ years, $\leq 50 \mu \mathrm{g} / \mathrm{L}$ and $\geq 10$ years, and $>50 \mu \mathrm{g} / \mathrm{L}$ and $\geq 10$ years) adjusted for other factors. We did not find any association with overall hypertension or with systolic or diastolic hypertension or pulse pressure separately. Low dose seems to have no effect regardless of length of exposure (analysis not shown).

Finally, we performed the analysis by $\leq 50 \mu \mathrm{g} / \mathrm{L}$ and $>50 \mu \mathrm{g} / \mathrm{L}$ arsenic exposures in $<10$ years of duration and by $\leq 50 \mu \mathrm{g} / \mathrm{L}$ and $>50 \mu \mathrm{g} / \mathrm{L}$ arsenic exposures in $\geq 10$ years of duration to that of overall hypertension and pulse pressure separately. Results are shown in Table 4; similar to the findings in Table 2, participants exposed to arsenic concentration $>50 \mu \mathrm{g} / \mathrm{L}$ for $>10$ years had an increased pulse pressure to that of participants exposed to arsenic concentration $\leq 50 \mu \mathrm{g} / \mathrm{L}$ for $>10$ years when adjusted for other factors.

Table 4. Association of arsenic and duration of its exposure separately with overall hypertension and increased pulse pressure $(n=993)$.

\begin{tabular}{|c|c|c|c|c|c|c|c|}
\hline \multirow{2}{*}{$\begin{array}{c}\text { Duration of } \\
\text { Arsenic } \\
\text { Exposure } \\
\text { (years) }\end{array}$} & \multirow{2}{*}{$\begin{array}{c}\text { Arsenic } \\
\text { Conc. }(\mu \mathrm{g} / \mathrm{L})\end{array}$} & \multirow{2}{*}{$\begin{array}{l}\text { No. of Overall } \\
\text { HTN }{ }^{\varphi} \text { Cases }\end{array}$} & \multicolumn{2}{|c|}{$\begin{array}{c}\text { Overall } \\
\text { Hypertension }\end{array}$} & \multirow{2}{*}{$\begin{array}{l}\text { No. of Pulse } \\
\text { Pressure } \\
\text { cases }\end{array}$} & \multicolumn{2}{|c|}{ Pulse pressure * } \\
\hline & & & $\begin{array}{l}\text { Adj. } \\
\text { OR }\end{array}$ & $95 \%$ CI & & Adj. OR & 95\% CI \\
\hline \multirow{2}{*}{$<10$} & $\leq 50^{\dagger}$ & 12 & - & - & 7 & - & - \\
\hline & $>50$ & 10 & 2.05 & $0.61-6.87$ & 12 & 2.35 & $0.67-8.30$ \\
\hline \multirow{2}{*}{$\geq 10$} & $\leq 50^{\dagger}$ & 31 & - & - & 8 & - & - \\
\hline & $>50$ & 13 & 0.72 & $0.32-1.60$ & 14 & 5.25 & $1.41-19.51$ \\
\hline
\end{tabular}

${ }^{\varphi}$ HTN: overall Hypertension; ${ }^{*}$ Pulse pressure was categorized as $<55$ and $\geq 55 \mathrm{mmHg} ;{ }^{\dagger}$ Reference category. Adjusted for age, sex, education, marital status, religion, monthly income, and BMI; ${ }^{* *}$ Crude odds ratios in $<10$ years and $\geq 10$ years group for overall hypertension were 0.79 (CI: 0.33-1.88) and 0.52 (CI: 0.27-1.01), respectively; and crude odds ratios in $<10$ years and $\geq 10$ years group for increased pulse pressure were 1.69 (CI: 0.65-4.40) and 2.35 (CI: 0.97-5.68), respectively.

We also modelled a sensitivity analysis excluding participants with lesser duration of exposure ( $<2$ and $<5$ years) and did not find any difference in the occurrence of overall, systolic and diastolic hypertension and pulse pressure.

\section{Discussion}

Arsenic exposure was found to be strongly associated with increased pulse pressure in our study and the association tended to be stronger in the participants with higher quartiles and longer duration of high arsenic exposure. Overall hypertension and systolic or diastolic hypertension were not associated with any level or duration of arsenic exposure in this study, except by considering systolic blood pressure and arsenic exposure as continuous variables. Our findings are similar to other studies conducted by Chen et al. in 2007 and by Zhang et al. in 2012; they observed an association between arsenic exposure and increased pulse pressure [17,42]. A recent systematic review and meta-analysis also reported an inconclusive association between arsenic and hypertension [43]. In our study, Hindu participants were more likely to be hypertensive because higher proportions of Hindus had a relatively 
higher weight compared to Muslims and the association between obesity and hypertension is well recognized [44]. Therefore, any association between hypertension as well as pulse pressure and arsenic exposures might be accentuated by higher BMI and confounded by participants religion.

Increased pulse pressure in adults can occur due to atherosclerotic changes. In atherosclerosis, lacking arterial elasticity could potentially leads to arterial stiffness in the arterial walls and may subsequently increase the pulse pressure [45]. Pulse pressure is a growing concern as a risk factor for coronary artery disease and the relationship may be bidirectional [46]. One study describes pulse pressure as an independent predictive risk factor for death from cardiovascular disease, coronary heart disease, and all-cause mortality [47].

The important issue is how arsenic exposure could influence in increasing pulse pressure. The pathophysiology of arsenic induced increased pulse pressure is largely unknown. Possible explanations involve vascular endothelium and smooth muscles as primary targets of arsenic toxicity, which then promotes inflammatory activity $[17,48]$. Chronic arsenic exposure in animals can cause decreased stroke volume and cardiac output and increased vascular resistance [49]. Arsenite (trivalent arsenic or arsenic trioxide) induces oxidant accumulation and subsequently activates tyrosine phosphorylation that causes proliferation of vascular cells thereby causing cardiovascular diseases [48].

In this study, we used a large population dataset that includes arsenic concentration in individual participant's drinking water, duration of exposure, arsenical skin lesions, and information on hypertension along with other socio-demographic factors and co-morbidity status. The study population were well described and the source of drinking water was well identified at the household level. Also, the study participants were recruited at the household level from their residing unions, so exposed and non-exposed participants were similar in their socioeconomic status, lifestyle, occupation, dietary and salt intake.

A number of previous studies from different parts of the world including Bangladesh reported significant associations between arsenic exposure and hypertension. A recent Taiwanese study found increased risk of hypertension following chronic exposure to drinking water arsenic [50]. Tseng et al. reported that an individual's capacity to complete methylation of inorganic arsenic is associated with peripheral vascular disease and hypertension [51]. In 1999, Rahman et al. reported a dose response relationship between drinking water arsenic and hypertension [36]. Similarly, a Chinese study also confirmed a dose response relationship with drinking water arsenic exposure and systolic blood pressure [52]. Hsueh et al. described a relationship between NAD(P)H oxidase, manganese superoxide dismutase (MnSOD) and endothelial nitric oxide synthase (e-NOS) polymorphisms and arsenic related hypertension [53]. Although these studies concentrated on drinking water arsenic via artesian wells, tube well or tap water, other sources of drinking water in adults such as use of bottled water and arsenic treated water might dilute the association. It is surprising that we were not able to detect an association with systolic, diastolic or overall hypertension in our study despite these previous results. Given that most of these previous studies were ecological in nature, the association may be subject to confounding [17].

A recent Bangladeshi study reported that arsenic exposure and cigarette smoking was synergistic for ischemic and other heart diseases [54]. However in our study, the lack of association may be due to more participation by females who were less likely to be smokers and less likely to have hypertension $[55,56]$. 
Moreover, a gender differences in biotransformation of arsenic methylation was observed previously and arsenic methylation occurred more efficiently in females [57,58].

Despite important public health and research implications, this study possesses some limitations. Firstly, it would have been desirable to have directly measured individual exposure data over time, because the available water samples reflected only a particular point in time and not the historical exposure. Nevertheless, in the absence of any reliable information on past exposure, it was essential to assume that arsenic concentrations from the tube wells had been relatively constant over time. The historical consistency of arsenic concentration is of particular concern with shallow ground water, which might be subject to greater fluctuation than water from a deeper well. Any fluctuation of arsenic concentrations is likely to affect the cases and controls equally. Secondly, duration of tubewell water use was self-reported recall by the participants as there was no reliable data especially on the duration of contaminated water use. Thirdly, this is a cross-sectional study and causality between drinking water arsenic and development of hypertension cannot be completely ensured. The study findings provide clues for further analytical studies. Furthermore, this study did not measure any other potential trace elements in drinking water which might have an influence on blood pressure. Further prospective epidemiologic studies in population exposed to a wide range of inorganic arsenic excluding other trace elements are needed to confirm this association, preferably in a group with individual measures of exposure over time.

In this study, two third of the participants were female. In Bangladesh, especially in rural areas, most of the males are engaged in income generation to meet their daily requirement. As our research team visited the households during the daytime, most of the male members of the households were at work. It was therefore relevant to collect data on contraceptive pill uses by the female members because of its relationship with hypertension although use of contraceptive pills are rare in rural Bangladesh [36]. We did not find any increased prevalence of hypertension by gender, therefore contraceptive pill use is unlikely to be a confounder.

\section{Conclusions}

Arsenic exposure from drinking water, even at lower levels $(23-63 \mu \mathrm{g} / \mathrm{L})$, was positively associated with high pulse pressure. A dose-response pattern was also observed between arsenic exposure as quartile and increased pulse pressure. We did not find any association between chronic arsenic exposure and overall hypertension or with systolic and diastolic hypertension separately. The study findings added further information over previous similar works. Future analytical studies would be invaluable in characterising the association and its mechanism.

\section{Acknowledgements}

We are grateful to our research team who worked very hard to collect quality data and successfully completed the study in time. We also acknowledge the contribution of Ministry of Health and Family Welfare, People's Republic of Bangladesh under the Non-Communicable Diseases and other Public Health Interventions (NCD \& OPHI) department for their financial support to conduct the study. 


\section{Conflicts of Interest}

The authors declare no conflict of interest.

\section{References}

1. Chen, C.J.; Hsueh, Y.M.; Lai, M.S.; Shyu, M.P.; Chen, S.Y.; Wu, M.M.; Kuo, T.L.; Tai, T.Y. Increased prevalence of hypertension and long-term arsenic exposure. Hypertension 1995, 25, 53-60.

2. Tamas, M.J.; Wysocki, R. Mechanisms involved in metalloid transport and tolerance acquisition. Curr. Genet. 2001, 40, 2-12.

3. Smith, A.H.; Hopenhayn-Rich, C.; Bates, M.N.; Goeden, H.M.; Hertz-Picciotto, I.; Duggan, H.M.; Wood, R.; Kosnett, M.J.; Smith, M.T. Cancer risks from arsenic in drinking water. Environ. Health Perspect. 1992, 97, 259-267.

4. Haque, R.; Mazumder, D.N.; Samanta, S.; Ghosh, N.; Kalman, D.; Smith, M.M.; Mitra, S.; Santra, A.; Lahiri, S.; Das, S.; De, B.K.; Smith, A.H. Arsenic in drinking water and skin lesions: Dose-response data from West Bengal, India. Epidemiology 2003, 14, 174-182.

5. Navas-Acien, A.; Silbergeld, E.K.; Streeter, R.A.; Clark, J.M.; Burke, T.A.; Guallar, E. Arsenic exposure and Type 2 diabetes: A systematic review of the experimental and epidemiologic evidence. Environ. Health Perspect. 2006, 114, 641-648.

6. Smith, A.H.; Steinmaus, C.M. Health effects of arsenic and chromium in drinking water: Recent human findings. Annu. Rev. Public Health 2009, 30, 107-122.

7. Anetor, J.I.; Wanibuchi, H.; Fukushima, S. Arsenic exposure and its health effects and risk of cancer in developing countries: Micronutrients as host defence. Asian Pac. J. Cancer Prev. 2007, $8,13-23$.

8. Abernathy, C.O.; Thomas, D.J.; Calderon, R.L. Health effects and risk assessment of arsenic. J. Nutr. 2003, 133, 1536S-1538S.

9. Chiou, H.Y.; Chiou, S.T.; Hsu, Y.H.; Chou, Y.L.; Tseng, C.H.; Wei, M.L.; Chen, C.J. Incidence of transitional cell carcinoma and arsenic in drinking water: A follow-up study of 8,102 residents in an arseniasis-endemic area in northeastern Taiwan. Am. J. Epidemiol. 2001, 153, 411-418.

10. Yu, R.C.; Hsu, K.H.; Chen, C.J.; Froines, J.R. Arsenic methylation capacity and skin cancer. Cancer Epidemiol. Biomarkers Prev. 2000, 9, 1259-1262.

11. Milton, A.H.; Smith, W.; Rahman, B.; Hasan, Z.; Kulsum, U.; Dear, K.; Rakibuddin, M.; Ali, A. Chronic arsenic exposure and adverse pregnancy outcomes in bangladesh. Epidemiology 2005, 16, 82-86.

12. Milton, A.H.; Shahidullah, S.M.; Smith, W.; Hossain, K.S.; Hasan, Z.; Ahmed, K.T. Association between chronic arsenic exposure and nutritional status among the women of child bearing age: A case-control study in Bangladesh. Int. J. Environ. Res. Public Health 2010, 7, 2811-2821.

13. Islam, M.R.; Khan, I.; Hassan, S.M.N.; McEvoy, M.; D’Este, C.; Attia, J.; Peel, R.; Sultana, M.; Akter, S.; Milton, A.H. Association between type 2 diabetes and chronic arsenic exposure in drinking water: A cross sectional study in Bangladesh. Environ. Health 2012, 11, doi:10.1186/1476-069X-11-38. 
14. Yang, C.Y. Does arsenic exposure increase the risk of development of peripheral vascular diseases in humans? J. Toxicol. Environ. Health A 2006, 69, 1797-1804.

15. Chang, C.C.; Ho, S.C.; Tsai, S.S.; Yang, C.Y. Ischemic heart disease mortality reduction in an arseniasis-endemic area in southwestern Taiwan after a switch in the tap-water supply system. J. Toxicol. Environ. Health A 2004, 67, 1353-1361.

16. Merriam-Webster. Definition of Hypertension. In Merriam-Webster's Medical Dictionary; Merriam Webster Mass Market: Miami, FL, USA, 1995.

17. Chen, Y.; Factor-Litvak, P.; Howe, G.R.; Graziano, J.H.; Brandt-Rauf, P.; Parvez, F.; van Geen, A.; Ahsan, H. Arsenic exposure from drinking water, dietary intakes of B Vitamins and folate, and risk of high blood pressure in Bangladesh: A population-based, cross-sectional study. Am. J. Epidemiol. 2007, 165, 541-552.

18. Kearney, P.M.; Whelton, M.; Reynolds, K.; Muntner, P.; Whelton, P.K.; He, J. Global burden of hypertension: Analysis of worldwide data. Lancet 2005, 365, 217-223.

19. Novo, S.; Lunetta, M.; Evola, S.; Novo, G. Role of ARBs in the blood hypertension therapy and prevention of cardiovascular events. Curr. Drug Targets 2009, 10, 20-25.

20. Sica, D.A. Endocrine causes of secondary hypertension. J. Clin. Hypertens (Greenwich) 2008, 10, 534-540.

21. Viera, A.J.; Neutze, D.M. Diagnosis of secondary hypertension: An age-based approach. Amer. Family Phys. 2010, 82, 1471-1478.

22. Carretero, O.A.; Oparil, S. Essential hypertension. Part I: Definition and etiology. Circulation 2000, 101, 329-335.

23. Kyrou, I.; Chrousos, G.P.; Tsigos, C. Stress, visceral obesity, and metabolic complications. Ann. NY Acad. Sci. 2006, 1083, 77-110.

24. Wofford, M.R.; Hall, J.E. Pathophysiology and treatment of obesity hypertension. Curr. Pharm. Design 2004, 10, 3621-3637.

25. Haslam, D.W.; James, W.P. Obesity. Lancet 2005, 366, 1197-1209.

26. Lackland, D.T.; Egan, B.M. Dietary salt restriction and blood pressure in clinical trials. Curr. Hypertens Rep. 2007, 9, 314-319.

27. Djousséa, L.; Mukamal, K.J. Alcohol consumption and risk of hypertension: Does the type of beverage or drinking pattern matter? Revista Española De Cardiología 2009, 62, 603-605.

28. Kosugi, T.; Nakagawa, T.; Kamath, D.; Johnson, R.J. Uric acid and hypertension: An age-related relationship? J. Hum. Hypertens 2009, 23, doi:10.1038/jhh.2008.110.

29. Luma, G.B.; Spiotta, R.T. Hypertension in children and adolescents. Am. Fam. Physician 2006, $73,1558-1568$.

30. Uchiyama, M. Mild hypertension in children. Nippon Rinsho 2008, 66, 1477-1480.

31. Segura, J.; Ruilope, L.M. Obesity, essential hypertension and renin-angiotensin system. Public Health Nutr. 2007, 10, 1151-1155.

32. Sorof, J.; Daniels, S. Obesity hypertension in children: A problem of epidemic proportions. Hypertension 2002, 40, 441-447.

33. Dastgiri, S.; Mosaferi, M.; Fizi, M.A.; Olfati, N.; Zolali, S.; Pouladi, N.; Azarfam, P. Arsenic exposure, dermatological lesions, hypertension, and chromosomal abnormalities among people in a rural community of northwest Iran. J. Health Popul. Nutr. 2010, 28, 14-22. 
34. Datta, D.V.; Mitra, S.K.; Chhuttani, P.N.; Chakravarti, R.N. Chronic oral arsenic intoxication as a possible aetiological factor in idiopathic portal hypertension (non-cirrhotic portal fibrosis) in India. Gut 1979, 20, 378-384.

35. Chiou, H.Y.; Huang, W.I.; Su, C.L.; Chang, S.F.; Hsu, Y.H.; Chen, C.J. Dose-response relationship between prevalence of cerebrovascular disease and ingested inorganic arsenic. Stroke 1997, 28, 1717-1723.

36. Rahman, M.; Tondel, M.; Ahmad, S.A.; Chowdhury, I.A.; Faruquee, M.H.; Axelson, O. Hypertension and arsenic exposure in Bangladesh. Hypertension 1999, 33, 74-78.

37. Chen, C.J.; Wang, S.L.; Chiou, J.M.; Tseng, C.H.; Chiou, H.Y.; Hsueh, Y.M.; Chen, S.Y.; $\mathrm{Wu}$, M.M.; Lai, M.S. Arsenic and diabetes and hypertension in human populations: A review. Toxicol. Appl. Pharmacol. 2007, 222, 298-304.

38. American Public Health Association. Standard Methods for the Examination of Water and Wastewater; 19th ed.; American Public Health Association, American Water Works Association and Water Environment Federation: Washington, DC, USA, 1995.

39. U.S. Department of Health and Human Services, National Institute of Health. The fifth report of the joint national committee on detection, evaluation, and treatment of high blood pressure (JNC V). Arch. Intern. Med. 1993, 153, 149-152.

40. Rose, G.A.; Blackburn, H.; Gillum, R.F.; Prineas, R.J. Cardiovascular Survey Methods: World Health Organization; World Health Organization: Geneva, Switzerland, 1982; pp. 82-85.

41. Shetty, P.S. Body Mass Index, A Measurement of Chronic Energy Deficiency in Adults; Requirements of Ideal Nutritional Anthropometric Index; Food and Agricultural Organization: Rome, Italy, 1994.

42. Zhang, C.; Mao, G.; He, S.; Yang, Z.; Yang, W.; Zhang, X.; Qiu, W.; Ta, N.; Cao, L.; Yang, H.; et al. Relationship between long-term exposure to low-level arsenic in drinking water and the prevalence of abnormal blood pressure. J. Hazard. Mater. 2012, doi:10.1016/j.hazmat.2012.09.045.

43. Abir, T.; Rahman, B.; D’Este, C.; Farooq, A.; Milton, A.H. The association between chronic arsenic exposure and hypertension: A meta-analysis. J. Toxicol. 2012, doi:10.1155/2012/198793.

44. Rocchini, A.P. Obesity hypertension. Am. J. Hypertens. 2002, 15, 50S-52S.

45. Zureik, M.; Touboul, P.J.; Bonithon-Kopp, C.; Courbon, D.; Berr, C.; Leroux, C.; Ducimetiere, P. Cross-sectional and 4-year longitudinal associations between brachial pulse pressure and common carotid intima-media thickness in a general population: The EVA study. Stroke 1999, 30, 550-555.

46. Dart, A.M.; Kingwell, B.A. Pulse pressure-A review of mechanisms and clinical relevance. J. Am. Coll. Cardiol. 2001, 37, 975-984.

47. Domanski, M.; Norman, J.; Wolz, M.; Mitchell, G.; Pfeffer, M. Cardiovascular risk assessment using pulse pressure in the First National Health and Nutrition Examination Survey (NHANES I). Hypertension 2001, 38, 793-797.

48. Barchowsky, A.; Roussel, R.R.; Klei, L.R.; James, P.E.; Ganju, N.; Smith, K.R.; Dudek, E.J. Low levels of arsenic trioxide stimulate proliferative signals in primary vascular cells without activating stress effector pathways. Toxicol. Appl. Pharmacol. 1999, 159, 65-75.

49. Carmignani, M.; Boscolo, P.; Castellino, N. Metabolic fate and cardiovascular effects of arsenic in rats and rabbits chronically exposed to trivalent and pentavalent arsenic. Arch. Toxicol. Suppl. 1985, 8, 452-455. 
50. Wang, S.L.; Li, W.F.; Chen, C.J.; Huang, Y.L.; Chen, J.W.; Chang, K.H.; Tsai, L.Y.; Chou, K.M. Hypertension incidence after tap-water implementation: A 13-year follow-up study in the arseniasis-endemic area of southwestern Taiwan. Sci. Total Environ. 2011, 409, 4528-4535.

51. Tseng, C.H. Cardiovascular disease in arsenic-exposed subjects living in the arseniasishyperendemic areas in Taiwan. Atherosclerosis 2008, 199, 12-18.

52. Kwok, R.K.; Mendola, P.; Liu, Z.Y.; Savitz, D.A.; Heiss, G.; Ling, H.L.; Xia, Y.; Lobdell, D.; Zeng, D.; Thorp, J.M. J.; Creason, J.P.; Mumford, J.L. Drinking water arsenic exposure and blood pressure in healthy women of reproductive age in Inner Mongolia, China. Toxicol. Appl. Pharmacol. 2007, 222, 337-343.

53. Hsueh, Y.M.; Lin, P.; Chen, H.W.; Shiue, H.S.; Chung, C.J.; Tsai, C.T.; Huang, Y.K.; Chiou, H.Y.; Chen, C.J. Genetic polymorphisms of oxidative and antioxidant enzymes and arsenic-related hypertension. J. Toxicol. Environ. Health A 2005, 68, 1471-1484.

54. Chen, Y.; Graziano, J.H.; Parvez, F.; Liu, M.; Slavkovich, V.; Kalra, T.; Argos, M.; Islam, T.; Ahmed, A.; Rakibuz-Zaman, M.; Hasan, R.; Sarwar, G.L.; van Geen, A.; Ahsan, H. Arsenic exposure from drinking water and mortality from cardiovascular disease in Bangladesh: Prospective cohort study. BMJ 2011, doi:10.1136/bmj.d2431.

55. Van Minh, H.; Byass, P.; Chuc, N.T.K.; Wall, S. Gender differences in prevalence and socioeconomic determinants of hypertension: Findings from the WHO STEPs survey in a rural community of Vietnam. J. Hum. Hypertension 2006, 20, 109-115.

56. Mohsenin, V.; Yaggi, H.K.; Shah, N.; Dizura, J. The effect of gender on the prevalence of hypertension in obstructive sleep apnea. Sleep Med. 2009, 10, 759-762.

57. Lindberg, A.L.; Ekström, E.C.; Nermell, B.; Rahman, M.; Lönnerdal, B.; Persson, L.A.; Vahter, M. Gender and age differences in the metabolism of inorganic arsenic in a highly exposed population in Bangladesh. Environ. Res. 2008, 106, 110-120.

58. Vahter, M.; Åkesson, A.; Lidén, C.; Ceccatelli, S.; Berglund, M. Gender differences in the disposition and toxicity of metals. Environ. Res. 2007, 104, 85-95.

(C) 2012 by the authors; licensee MDPI, Basel, Switzerland. This article is an open access article distributed under the terms and conditions of the Creative Commons Attribution license (http://creativecommons.org/licenses/by/3.0/). 